\title{
Exploring Stressors of the University Faculty members: A Comparative Study
}

\author{
Dr. Mohammad Alboliteeh \\ Vice Deanship of Post Graduate and Scientific Research, \\ College of Nursing, University of Hail
}

\begin{abstract}
Stress is defined as a dynamic condition in which an individual is confronted with an opportunity, constraint, demand related to what he or she desires and for which the outcome is perceived to be both uncertain and important. This study focused on the manifestations and the sources of stress on faculty members of Hail University for the 2nd Semester of Academic Year 2018-2019. A quantitative-comparative approach was employed in this study. There were 236 faculty who had participated in the study resulting to $94.4 \%$ response rate. Data collection started from February 2019 to April 2019. To measure manifestations and the sources of stress, the Total Teacher Concern Inventory was used. This consists of 48 distinct statements. Weighted mean, Analysis of Variance (F-test), and (t-test) were used. All statistical analyses were performed at 0.05 level of significance. Results shows that the faculty disagreed that the sources of stress from work-related stressors (3.47). A significant difference between time management and sex (0.04) was determined. Likewise, a significant difference between gastrointestinal manifestations $(0.01)$, behavioral manifestations $(0.01)$ and the faculty's age was obtained.
\end{abstract}

Keywords: faculty stress, sources of stress, manifestation of stress

\section{INTRODUCTION}

Work stress is considered as a reaction to stimuli in a job that leads to negative consequences to the people who are exposed to them (Resick et al., 2007) and considered as a big threat to the quality of life and to physical and psychological well-being (Qazi \& Nazneen, 2016). The very idea of stress was introduced in 1936 by Hans Selye, who borrowed it via natural sciences (Selye, 1956). Hans's 'General Adaptation Syndrome' provoked quite a lot of research on this topic, primarily focusing stress and disease, i.e., noxiousness to tissues systems and adaptation response to tissues systems (Selye, 1956). Gmelch, Wilke, and Lovrich (1986) defined faculty stress as the faculty member's anticipation of his/her inability to respond sufficiently to a perceived demand, accompanied by the expectancy of negative consequence/s due to the insufficient response to work demand/s. Stress is a common phenomenon for all university faculty across all disciplines (Gmelch et al., 1986). The academic functions of university faculty are all-inclusive, which include teaching and mentoring students, preparing papers and presentations for both class lectures and research conferences, attending to the needs of one's college or department and so on (Tan, 2017). They also must deal with functions outside the academic setting: their family life, social life and other commitments (Tan, 2017). Given the numerous roles and responsibilities, the intense demands and the high expectations set to them, many university faculty experience significant levels of stress and have shown particular responses to stress, such as increased turnover intent, decreased job performance, decreased job satisfaction, increased anxiety and increased depression (Khan, Aqeel, \& Riaz, 2014; Pushpalatha, Rao \& Mallaiah, 2016). 
Gupta, Rao \& Mukherjee (2015) detailed that during the last decade, a fast growth has been observed in higher education institutions, particularly in developing countries, leading to higher competition and deteriorated organizational climate in most of the public and private sector universities (Rajarajeswari, 2010). Faculty stress is recognized as serious by virtually everyone who has studied the problem (Phillips and Matthew, 1980). Seldin (1987) stated that the academic environment of the 1980s had imposed surprisingly high levels of job stress on academics, and that the level of stress would continue to increase in future decades. In recent years, a number of substantial changes in the higher education sector (Aarrevaara et al., 2007) have significantly transformed the conditions under which the university teachers perform their jobs. Many researchers conducted their researches and presented a fair amount of comparison between stressful nature of teaching profession and other occupations (Iqbal and Kokash, 2011). Ahsan et al. (2009) conducted a study in Malaysia and found that the number of universities in Malaysia has increased tremendously in the past few years due to which the university academic staffs face more problems in their job. Almost all the universities are now setting new goals to compete with other universities as well as the academic staff are involving with the goal. This may cause the university academic staff to face plenty of stress and therefore affect their satisfaction and even their physical or mental health (Ahsan et al, 2009).

Seeing the teaching profession as one of the most stressful professions (Wiggins, 2015) the study's objectives were to assess the level on the sources of stress and extent of manifestation on the sources of stress among the faculty of the University of Hail. The difference between the demographic profile and the level of on the sources of stress, the sources of stress and the manifestations of stress is determined as well.

\section{METHODS}

The study used the quantitative-comparative approach of research in determining the difference between the demographic profile and the level of on the sources of stress and the manifestations of stress. The respondents of the study were the faculty of the University Hail, Kingdom of Saudi Arabia. Simple random sampling was employed resulting to 236 respondents with a $94.4 \%$ response rate. Exclusion criteria includes faculty that are teaching minor subjects.

Data collection started from February 2019 to April 2019 upon the approval of the authorities from the University of Hail. In compliance with research ethics protocol, the ethical principle of the informed consent, beneficence, respect for anonymity and confidentiality and respect for privacy were applied in the study. Approximately 10 - 15 minutes were provided to the respondents to answer the survey questionnaire. Immediately after gathering the data, the researcher collated, tabulated, analyzed and interpreted the results.

The researchers used the Total Teacher Concern Inventory (Fimian, 1984) to measure manifestations and the sources of stress. The survey questionnaire is composed of two (2) parts. The first part is on the respondents' demographic information. The second part is the faculty's causes of stress in relation to Time Management, Work-Related Stressors, Professional Distress, Discipline and Motivation, Professional Investment, Emotional Manifestations, Fatigue Manifestations, Cardiovascular Manifestations, Gastronomical Manifestations and Behavioral Manifestations. The questionnaire used a Likert's Scale of 5 (Strongly Agree), 4 (Agree), 3 (Undecided), 2 (Disagree) and 1 (Strongly Disagree).

The data gathered were tabulated (with the use of Microsoft Excel 2010), evaluated, analyzed and computed statistically using Statistical Package for Social Sciences Version 22 (SPSS 22). The frequency count and percentage were used to determine the profiles of the respondents as 
well as their characteristics. Weighted mean was utilized to determine the level on the sources of stress and extent of the manifestations on the sources of stress of faculty. Analysis of Variance (F-test) was employed to determine the significant difference in sources of stress and manifestation of stress in terms of the faculty's demographic information, except for sex. Sex was treated with t-test. All statistical analyses were performed at 0.05 level of significance.

\section{RESULTS}

Table 1

Demographic Profile of the Respondents $(\mathrm{N}=236)$

\begin{tabular}{|c|c|c|c|c|}
\hline Variable & Frequency & Percentage & Mean & SD \\
\hline \multicolumn{5}{|l|}{ a. Age } \\
\hline $21-25$ & 3 & 1.30 & \multirow{8}{*}{4.54} & \multirow{8}{*}{1.31} \\
\hline $26-30$ & 13 & 5.50 & & \\
\hline $31-35$ & 16 & 6.80 & & \\
\hline $36-40$ & 85 & 36.00 & & \\
\hline $41-45$ & 90 & 38.10 & & \\
\hline $46-50$ & 11 & 4.70 & & \\
\hline $51-55$ & 7 & 3.00 & & \\
\hline $56-60$ & 11 & 4.70 & & \\
\hline \multicolumn{5}{|c|}{ b. Teaching Experience } \\
\hline $1-4$ & 8 & 3.40 & \multirow{6}{*}{2.81} & \multirow{6}{*}{1.08} \\
\hline $5-10$ & 105 & 44.50 & & \\
\hline $11-15$ & 75 & 31.80 & & \\
\hline $15-20$ & 27 & 11.40 & & \\
\hline $21-25$ & 14 & 5.90 & & \\
\hline 26 and above & 7 & 3.00 & & \\
\hline \multicolumn{5}{|l|}{ c. Sex } \\
\hline Male & 138 & 58.50 & - & - \\
\hline Female & 98 & 41.50 & & \\
\hline
\end{tabular}

The age groups differed between the respondents, with most staff in the 41-45 years bracket (38.1\%) and it gradually decreases as the age bracket grows younger. In terms of the respondents' years teaching experience, a substantial proportion had 5-10 years of experience $(44.5 \%)$ and it diminishes as the faculty's teaching experience bracket grows more senior. Most of the respondents were male (58.5\%) while 41.5\% were female(Table 1).

Table 2

Level on the Sources of Stress $(\mathrm{N}=236)$

\begin{tabular}{lccc}
\hline \multicolumn{1}{c}{ Source } & Mean & SD & Interpretation \\
\hline Time Management & 3.39 & 0.84 & Undecided \\
Work-related & 3.47 & 0.78 & Disagree \\
Professional Distress & 3.38 & 0.85 & Undecided \\
Discipline and Motivation & 3.40 & 0.97 & Undecided \\
Professional Investment & 3.32 & 0.87 & Undecided \\
\hline
\end{tabular}

Legend: 1.00-1.80 Strongly Agree 1.81-2.60 Agree 2.61-3.40 Undecided 3.41-4.20 Disagree 4.21-5.00 Strongly Disagree

Table 2 exhibits the level on the sources of stress of the faculty. Apart from work-related stressors wherein the respondents disagree, the faculty were undecided regarding all the other 
sources of stress (time management, professional distress, discipline and motivation and professional investment).

Table 3

Extent of the Manifestations on the Sources of Stress ( $\mathrm{N}=236)$

\begin{tabular}{lccc}
\hline \multicolumn{1}{c}{ Manifestations } & Mean & SD & Interpretation \\
\hline Emotional & 3.33 & 0.82 & Undecided \\
Fatigue & 3.24 & 0.82 & Undecided \\
Cardiovascular & 3.25 & 0.99 & Undecided \\
Gastrointestinal & 3.18 & 1.03 & Undecided \\
Behavioral & 2.97 & 1.04 & Undecided \\
\hline
\end{tabular}

Legend: 1.00-1.80 Strongly Agree 1.81-2.60 Agree 2.61-3.40 Undecided 3.41-4.20 Disagree 4.21-5.00 Strongly Disagree

Table 3 displays the extent of the manifestations on the sources of stress of the faculty. As indicated in the table, the respondents were undecided in all the manifestations on the sources of stress.

Table 4

The Difference between Profile and Sources of Stress ( $\mathrm{N}=236)$

\begin{tabular}{llcccc}
\hline \multicolumn{1}{c}{ Profile } & \multicolumn{1}{c}{ Source of Stress } & df & Test value & p & Interpretation \\
\hline Age & Time Management & & (F) 0.68 & 0.69 & No significant difference \\
& Work-related & & (F) 1.042 & 0.40 & No significant difference \\
& Professional Distress & & (F) 1.38 & 0.22 & No significant difference \\
& Discipline and Motivation & 235 & (F) 0.41 & 0.90 & No significant difference \\
& Professional Investment & & (F) 1.45 & 0.19 & No significant difference \\
Teaching & Time Management & & (F) 0.76 & 0.58 & No significant difference \\
Experience & Work-related & & (F) 1.82 & 0.11 & No significant difference \\
& Professional Distress & & (F) 1.07 & 0.38 & No significant difference \\
& Discipline and Motivation & & (F) 0.83 & 0.53 & No significant difference \\
& Professional Investment & 235 & (F) 2.03 & 0.08 & No significant difference \\
Sex & Time Management & & (t) -2.00 & 0.04 & With significant \\
& Work-related & & dt -1.43 & 0.155 & No significant difference \\
& Professional Distress & 234 & (t) -1.43 & 0.15 & No significant difference \\
& Discipline and Motivation & & (t) -0.22 & 0.83 & No significant difference \\
& Professional Investment & & (t) -1.03 & 0.30 & No significant difference \\
\hline
\end{tabular}

Table 4 shows the significant difference in the sources of stress in terms of their profile. In terms age, time management yielded an F-value of 0.68 with a P-value of 0.69 ; for workrelated, the F-value is 1.042 with a P-value of 0.40 ; for professional distress, the F-value is 1.38 with a P-value of 0.22; for discipline and motivation the F-value is 0.41 with a P-value of 0.90 and for professional investment, the F-value is 1.45 with a P-value of 0.19 . Since all the Pvalues were greater than the 0.05 level of significance, this means that there is no significant difference between the sources of stress and age.

With respect to teaching experience, time management yielded an F-value of 0.76 with a Pvalue of 0.58; for work-related, the F-value is 1.82 with a P-value of 0.11 ; for professional distress the F-value is 1.07 with a P-value of 0.38 ; for discipline and motivation the F-value is 0.83 with a P-value of 0.53 and for professional investment the F-value is 2.03 with a P-value of 0.08. Since all the P-values were greater than the 0.05 level of significance, this means that there is no significant difference between the sources of stress and teaching experience. 
Regarding sex, for work-related yielded an t-value is -1.43 with a P-value of 0.155 ; for professional distress the t-value is -1.43 with a P-value of 0.15 ; for discipline and motivation the $t$-value is -0.22 with a $\mathrm{P}$-value of 0.83 and for professional investment the $\mathrm{t}$-value is -1.03 with a P-value of 0.83 . Since all the P-values were greater than the 0.05 level of significance, this means that there is no significant difference between the sources of stress and teaching experience. On the other hand, time management yielded an t-value of -2.00 with a P-value of 0.04. Since the P-value is less than 0.05 level of significance, these imply that there was a significant difference between in time management and sex.

Table 5

The Difference between Profile and Manifestation of Stress

\begin{tabular}{llcccc}
\hline \multicolumn{1}{c}{ Profile } & $\begin{array}{l}\text { Manifestation of } \\
\text { Stress }\end{array}$ & df & Test Value & p & Interpretation \\
\hline Age & Emotional & & (F) 0.48 & 0.85 & No significant difference \\
& Fatigue & (F) 1.37 & 0.22 & No significant difference \\
& Cardiovascular & 235 & (F) 0.35 & 0.93 & No significant difference \\
& Gastrointestinal & & (F) 2.62 & 0.01 & With significant difference \\
& Behavioral & (F) 2.60 & 0.01 & With significant difference \\
& Emotional & & (F) 1.06 & 0.38 & No significant difference \\
& Fatigue & & (F) 1.82 & 0.11 & No significant difference \\
& Cardiovascular & 235 & (F) 0.98 & 0.43 & No significant difference \\
& Gastrointestinal & & (F) 0.95 & 0.45 & No significant difference \\
& Behavioral & & (F) 1.45 & 0.21 & No significant difference \\
& Emotional & & (t) -0.39 & 0.70 & No significant difference \\
& Fatigue & (t) -0.85 & 0.40 & No significant difference \\
& Cardiovascular & (t) 1.34 & 0.18 & No significant difference \\
& Gastrointestinal & & (t) 0.83 & 0.41 & No significant difference \\
& Behavioral & (t) 0.05 & 0.96 & No significant difference \\
\cline { 2 - 6 }
\end{tabular}

Table 5 exhibits the significant difference in the manifestation of stress in terms of faculty's profile. Concerning age, emotional manifestations yielded an F-value of 0.48 with a P-value of 0.85; for fatigue manifestations, the F-value is 1.37 with a P-value of 0.22 and for cardiovascular manifestations, the F-value is 0.35 with a P-value of 0.93 . Since all the P-values were greater than the 0.05 level of significance, this means that there is no significant difference between the manifestation of stress in terms of the faculty's age. Conversely, gastrointestinal manifestations yielded the F-value is 2.62 with a P-value of 0.01 and for behavioral manifestations, the F-value is 2.60 with a P-value of 0.01 . Since the P-values were less than 0.05 level of significance, these imply that there was a significant difference between the manifestation of stress in terms of the faculty's age

Relating to teaching experience, emotional manifestations yielded an F-value of 1.06 with a Pvalue of 0.38; for fatigue manifestations, the F-value is 1.82 with a P-value of 0.11 ; for cardiovascular manifestations, the F-value is 0.98 with a P-value of 0.43 ; for gastrointestinal manifestations, the F-value is 0.95 with a P-value of 0.45 and for behavioral manifestations, the F-value is 1.45 with a P-value of 0.21 . Since all the P-values were greater than the 0.05 level of significance, this means that there is no significant difference between the manifestation of stress in terms of the faculty's teaching experience.

Pertaining to sex, emotional manifestations yielded an t-value of -0.39 with a P-value of 0.70 ; for fatigue manifestations, the t-value is -0.39 with a P-value of 0.40 ; for cardiovascular manifestations, the t-value is 1.34 with a P-value of 0.18 ; for gastrointestinal manifestations, the t-value is 0.83 with a P-value of 0.41 and for behavioral manifestations, the t-value is 0.05 with a P-value of 0.96 . Since all the P-values were greater than the 0.05 level of significance, 
this means that there is no significant difference between the manifestation of stress in terms of the faculty's sex.

\section{DISCUSSION}

The aim of this study was to assess the sources of stress and manifestation of stress experienced by the faculty of the University of Hail. The findings of the study revealed the respondents disagree that work-related concerns are the sources of stress. This indicates that the faculty have the time to prepare for their lessons/responsibilities; there is sufficiently time for work; the pace of the school day is measured; the caseload/class is sensible; there is decent administrative paperwork and the personal priorities of the faculty are being reinforced. Numerous studies support this finding. A recent study Hong Kong indicated that the more the job becomes an endeavor, the greater the academic's institutional commitment to the university (Horta et al., 2019). Therefore, work-related manifestations are unlikely to be seen the faculty. This may be due to Hong Kong's competitive working culture and performativity oriented higher education system. Contrarywise, the study of Olivier et al. (2003) construed that work-related stressors have been reported in their faculty. The introduction of rationalization (right sizing) and the new learner-teacher ratios has resulted in teachers having to deal with extremely large classes. According to the authors, the faculty's complaints were the demands of having to deal with large numbers of learners, having to tolerate a high noise level and general rowdiness in the class; lacking space, infrastructure and resources.

Research findings denotes that the faculty were undecided regarding the emotional, fatigue, cardiovascular, gastrointestinal and behavioral manifestations of stress. This implies that the respondents are unresolved concerning these manifestations. This finding is in opposition to the studies of Olivier et al. (2003), and Maslach, Schaufeli and Leiter (2001). Emotional manifestations are caused feelings of depression in which the faculty were experiencing (Olivier et al., 2003). Emotional exhaustion represents the stress dimension of burnout and often manifests itself by increased fatigue, depression, emotional and cognitive distancing from work resulting in adverse work outcomes such as satisfaction and performance (Maslach, Schaufeli \& Leiter, 2001). Stress manifests itself mainly on the emotional, cardiovascular, gastronomical symptoms, fatigue and behavioral levels of teachers, at different levels of incidence and intensity and is caused mainly by their job (Olivier et al., 2003).

The findings also reflect significant difference between in time management and sex concerning the sources of stress. This denotes that when it involves over-committing, becoming impatient, multitasking, being apprehensive, rushed speech and thinking unrelated matters during conversations, there is a variation in gender. This finding is corroborated by Manthei (1988) who has reported that female teachers experience more stress than male teachers due to job overload. Further, Payne (1987) has found that women teachers reported significantly more stress concerning time management. Women faculty have expressed their own vulnerability to stress in fields where they are traditionally under-represented (i.e. science, mathematics, and engineering) (Hutchins \& Rainbolt, 2017) and often face bias to their professional inclusion and legitimacy (Dasgupta, 2011). Hutchins (2015) suggested that male faculty reported using avoidant coping methods such as dissociating from stress through alcohol or other substance abuse and working harder.

Study results further revealed that a significant difference between faculty's age and gastrointestinal and behavioral manifestations. This implies that depending on the faculty's age, they respond to stress with stomach pain/cramps and by calling in sick or by using overthe-counter drugs/prescription drugs. This finding validates the studies of Wimsatt \& Langley (2009) and Gmelch et al. (1986). Younger faculty feel greater pressure to show their 
competencies in different aspects of their academic work, especially when competition for academic promotion is extremely intense (Gmelch et al., 1986). Furthermore, younger faculty feel more stress as they face the challenge of balancing their personal and professional commitments (Wimsatt \& Langley, 2009). Ranking of the emotional effects of stress as highest to lowest were the following: 1) irritability; 2) apprehension; 3) depression; 4) anger; and 5) less tolerance to others according to Colacion-Quiros \& Gemora (2016.) Among the emotional effects of stress among the respondents of this study, irritability is perhaps a clear result of their varied behavioral responses to both physiological as well as behavioral stimuli - the latter including areas of environmental, situational, sociological, and emotional stimulus (ColacionQuiros \& Gemora, 2016). On the other hand, Dela Peña (2011) studied the work stress among education professors in Philippines and specified that no significant relationships were found between work stress and age.

Some authors point out that affect the manifestation of stress. These include work overload (Gupta, Rao, \& Mukherjee, 2015), work-life imbalance (Pasay-an et al., 2019), decreased job satisfaction (Brewer \& McMahan-Landers, 2013), work overload (Abbas \& Roger, 2013; Gupta, Rao \& Mukherjee, 2015), increased number of students to teach (Gartia \& Sharma, 2013; Jamison \& Enrera, 2015), lack of administrative and colleague support (Gupta et al., 2015) and lack of university funding, resources and recognition (Gupta et al., 2015). Other demographic and education-related factors such as age (Akbar \& Akhter, 2011), academic ranks (ColacionQuiros \& Gemora, 2016) and years of teaching experience (Gartia \& Sharma, 2013) also contribute to their stress levels. Moreover, researchers found that stress is related to lower ratings of job performance (Hutchins 2015), lower student evaluations of teaching performance (Brems et al. 1994), and higher levels of faculty anxiety (Topping and Kimmel 1985). Clark,Vardeman, and Barba (2012) also found that rank and years in service predicted faculty stress experiences. Parkman and Beard (2008) discussed the increased risk of losing top faculty talent because of persistent stress concerns. Stress often leads them to experience increased levels burnout, and decreased job performance and satisfaction overtime (Whitman and Shanine 2012).

\section{IMPLICATIONS}

As teachers, it is crucial to identify situations that might reverse anxiety and stress among faculty members. Educational heads do need to provide support to the teaching faculty members to relieve stress at the workplace.

The finding of this study can prove to be useful for researchers, academicians, heads of the institutions, teachers and educational policy makers. For the heads of the institutions, the study enables understanding of the identification of stress teaching professionals and its relationship to their work role and job satisfaction. Further, the study helps to identify the health status of faculty members, the health practices followed by them and could positively the working conditions. Information produced from this study has the potential to increase job satisfaction and to reduce the turnover rate for experienced as well as the new teaching professionals. An understanding of stress in management teaching professionals may not only form the basis of stress analysis but may also be useful in rationalizing stress behavior and formulating coping strategies for the entire teaching population. It may also help in developing sound overall workplace strategies for management faculty members. Preventive and restorative measures may be designed and adopted to reduce and overcome psychological stress in faculty members. The institution should encourage the faculty to formulate stress management activity proposals and programs that would help the faculty in managing their stress and to function at the highest. Proper delegation and channeling of work should be encouraged since one of the common causes of stress is having to take on other people's work 
so that faculty members would be concentrating on the jobs fitted for them, and would give consideration to faculty near forced retirement age to enjoy minimal load and less designation or assignment. Stress management should form part of the curriculum of potential teachers and schools should organize workshops for teachers on how to deal with excess stress.

For educational policy makers, the finding of this study may be utilized by clinical psychologists, counselors, doctors and nurse to bring about appropriate adjustments in health awareness programs. The Ministry of Education, Ministry of Health, policy makers, voluntary bodies as NGOs can also benefit from this study enabling them to act as mediators between management institutes and faculty members to formulate standards for ensuring conducive environment at the workplace and flexible work culture. Educational administrators may be greatly benefited by the findings of the study whereby can design programs to overcome stress thus uplifting education standards.

For researchers, the results of this study can contribute to the knowledge relating to stress and coping strategies to manage them. It can provide a background and theoretical base for future studies. Our study establishes several opportunities for future research. This study was confined to the University of Hail; hence a similar study can be conducted to a larger geographical area and with larger samples for statistical generalizability. The findings of this study have found only a couple of difference in faculty profile and sources/manifestations of stress. A similar study can also be conducted relating personality characteristics, job commitment, leadership styles, and coping strategies. Future research should also focus on the impact of political/economic change as a source for faculty stress and alternatives for rich communication among faculty and between faculty and students in an otherwise electronic environment.

\section{CONCLUSIONS}

The results of this investigation indicated that the respondents disagree that work-related concerns are the sources of stress. Research findings denotes that the faculty were undecided regarding the emotional, fatigue, cardiovascular, gastrointestinal and behavioral manifestations of stress. The findings also reflect significant difference between in time management and sex concerning the sources of stress. Study results further revealed that a significant difference between faculty's age and gastrointestinal and behavioral manifestations.

It is recommended that all the universities should have stress audit on routine basis so that the stressors can be identified, and appropriate individual and organizational interventions can be made accordingly. The universities must ensure that their faculty members are attending faculty development program at least once in a year related to their field of specialization. The universities should have proper rules regulations and policies to create a congenial environment and must ensure that their rules regulations and procedures laid down must be strictly implemented so that the faculty members should feel comfortable. Universities must ensure that the faculty members are engaged in teaching, research and academic administration related work only. All universities should ensure proper pay package to the faculty members to avoid their exploitation and must induce element of job security. Proper career programs should be implemented in all the universities. These recommendations if implemented, may be helpful to reduce stress level among the faculty members and may ensure high level of organizational commitment among the faculty members that rightfully deserves a proud place in the community. 


\section{References}

Aarrevaara, T., Arimoto, A., Balbechevsky, E., Brennan, J., Graça, M., Harman, G., ... \& Machado, M. D. L. (2007). The changing conditions for academic work and careers in select countries. Incher-Kassel, International Centre for Higher Education Research Kassel.

Abbas, S. G., \& Roger, A. (2013). The impact of work overload and coping mechanisms on different dimensions of stress among university teachers. @ GRH, (3), 93-118.

Ahsan, N., Abdullah, Z., Fie, D. Y. G., \& Alam, S. S. (2009). A study of job stress on job satisfaction among university staff in Malaysia: Empirical study. European journal of social sciences, 8(1), 121-131.

Akbar, A., \& Akhter, W. (2011). Faculty stress at higher education: A study on the business schools of Pakistan. World Academy of Science, Engineering and Technology, 1082.

Brems, C., Baldwin, M. R., Davis, L., \& Namyniuk, L. (1994). The imposter syndrome as relatedto teaching evaluations and advising relationships of university faculty members. The Journal of Higher Education, 65(2), 183193.

Brewer, E., \& McMaha-Landers, J. (2003). The Relationship Between Job Stress and Job Satisfaction of Industrial and Technical Teacher Educators. Journal of Career and Technical Education, 20(1).

Clark, M., Vardeman, K., \& Barba, S. (2014). Perceived inadequacy: A study of the imposter phenomenon among college and research librarians.

Colacion-Quiros, H., \& Gemora, R. B. (2016). Causes and effects of stress among faculty members in a state university. Asia Pacific Journal of Multidisciplinary Research, 4(1).

Dasgupta, N. (2011). Ingroup experts and peers as social vaccines who inoculate the self concept: The stereotype inoculation model. Psychological Inquiry, 22(4), 231-246.

Dela Peña, S. C. III. (2011). Spirituality and work stress of teacher education institution faculty in Cagayan de Oro City, Philippines. IAMURE International Journal of Multidisciplinary Research, 2, 1-17. https://doi.org/10.7718/iamure.v2i1.56

Fimian, M. J. (1984). The development of an instrument to measure occupational stress in teachers: The Teacher Stress Inventory. Journal of Occupational Psychology, 57(4), 277293.

Gartia, R., \& Sharma, S. (2013). Stress among teacher educators from self financing colleges of education. International Journal of Research Pedagogy and Technology in Education and Movement Sciences, 1(3), 221-232.

Gmelch, W. H., Wilke, P. K., \& Lovrich, N. P. (1986). Dimensions of stress among university faculty: Factor-analytic results from a national study. Research in higher education, 24(3), 266-286.

Gupta, V., Rao, E., \& Mukherjee, R. (2015). Occupational stress amongst faculty members: A review of literature. International Journal of Research and Development-A Management Review, 4(2), 18-27.

Horta, H., Jung, J., Zhang, L. F., \& Postiglione, G. A. (2019). Academics' job-related stress and institutional commitment in Hong Kong universities. Tertiary Education and Management, 1-22.

Hutchins, H. M. (2015). Outing the imposter: A study exploring imposter phenomenon among higher education faculty. New Horizons in Adult Education and Human Resource Development, 27(2), 3-12.

Hutchins, H. M., \& Rainbolt, H. (2017). What triggers imposter phenomenon among academic faculty? A critical incident study exploring antecedents, coping, and development opportunities. Human Resource Development International, 20(3), 194-214.

Iqbal, A., \& Kokash, H. (2011). Faculty Perception of Stress and Coping Strategies in a Saudi Private University: An Exploratory Study. International Education Studies, 4(3), 137149.

Jamison, M. R., \& Enrera, J. A. (2015). Factors affecting work productivity among the female faculty of allied medical health colleges of University of Hail, Saudi Arabia. IOSR J Nurs Health Sci, 4(6), 25-39.

Khan, E. A., Aqeel, M., \& Riaz, M. A. (2014). Impact of job stress on job attitudes and life satisfaction in college lecturers. International journal of information and education Technology, 4(3), 270.

Manthei, R. (1988). School counselors and jobrelated stress, New Zealand Educational Studies, 22, $189-200$.

Maslach, C., Schaufeli, W. B., \& Leiter, M. P. (2001). Job burnout. Annual review of psychology, 52(1), 397-422. 
Olivier, M. A. J., \& Venter, D. J. L. (2003). The extent and causes of stress in teachers in the George region. South African Journal of Education, 23(3), 186-192.

Parkman, A., \& Beard, R. (2008). Succession planning and the imposter phenomenon in higher education. CUPAHR Journal, 59(2), 29-36.

Pasay-an, e., Pangket, P., Nialla, J., Laban, L.(2014). Work Life Balance Among Nurse Educators Towards Quality Life: A Mixed Method Study. International Journal of Sciences: Basic and Applied Research 18 (1)

Payne, R. (1987). Dimensions of occupational stress in West Indian secondary school teachers, British Journal of Educational Psychology,57,147-58.

Pushpalatha, K., Rao, P. G., \& Mallaiah, T. Y. (2016). Performance Appraisal System in Medical College Libraries in Karnataka State-A study.

Phillips, B. N., \& Lee, M. (1980). The changing role of the American teacher: Current and future sources of stress. White collar and professional stress, 93-111.

Qazi, S., \& Nazneen, A. (2016). Comparative study of organizational role stress and organizational commitment among the university faculty members of India and Saudi Arabia. European Scientific Journal, 12(31), 108-127.

Rajarajeswari, S. (2010). Role Stress Among The Aided And Self Financing College Teachers: A Discriminant Analysis. Global Management Review, 4(4).

Resick, C. J., Baltes, B. B., \& Shantz, C. W. (2007). Person-organization fit and work-related attitudes and decisions: Examining interactive effects with job fit and conscientiousness. Journal of applied psychology, 92(5), 1446.

Selye, H. (1956). The stress of life. New York, Mc Gran-Hill Book Company.

Seldin, P. (1987). Research findings on causes of academic stress. New directions for teaching and learning, 1987(29), 13-21.

Tan, J. S. T. (2017). Factors affecting stress among faculty members of public universities in the Philippines: A multiple regression analysis. International Journal of Psychological Studies, 9(3).

Topping, M. E., \& Kimmel, E. B. (1985). The imposter phenomenon: Feeling phony. Academic Psychology Bulletin.

Whitman, M. V., \& Shanine, K. K. (2012). Revisiting the impostor phenomenon: How individuals cope with feelings of being in over their heads. In The role of the economic crisis on occupational stress and well being (pp. 177-212). Emerald Group Publishing Limited.

Wiggins, K. (2015). Teaching is among the "top three most stressed occupations". Times Educational Supplement.

Wimsatt, L., Trice, A., \& Langley, D. (2009). Faculty Perspectives on Academic Work and Administrative Burden: Implications for the Design of Effective Support Services. Journal of research administration, 40(1), 71-89. 